Genome Insight Plant Genetics

\title{
Structural and evolutive features of the Plinia phitrantha and P. cauliflora plastid genomes and evolutionary relationships within tribe Myrteae (Myrtaceae)
}

\author{
Lilian de Oliveira Machado ${ }^{1}$, , Valdir Marcos Stefenon ${ }^{1}$, Leila do Nascimento Vieira ${ }^{2}$, \\ Rubens Onofre Nodari ${ }^{1}$ \\ ${ }^{1}$ Universidade Federal de Santa Catarina, Departamento de Fitotecnia, Programa de Pós-graduação \\ em Recursos Genéticos Vegetais, Florianópolis, SC, Brazil. \\ ${ }^{2}$ Universidade Federal do Paraná, Departamento de Botânica, Curitiba, PR, Brazil.
}

\begin{abstract}
Plinia phitrantha and P.cauliflora are Myrtaceae species with recognized horticultural and pharmacological potential. Nevertheless, studies on molecular genetics and the evolution of these species are absent in the literature. In this study, we report the complete plastid genome sequence of these species and an analysis of structural and evolutive features of the plastid genome within the tribe Myrteae. The two plastid genomes present the conserved quadripartite structure and are similar to already reported plastid genomes of Myrteae species concerning the size, number, and order of the genes. A total of 69-70 SSR loci, 353 single nucleotide polymorphisms, and 574 indels were identified in P. phitrantha and P. caulifora. Observed evolutive features of the plastid genomes support the development of programs for the conservation and breeding of Plinia. The phylogenomic analysis based on the complete plastid genome sequence of 15 Myrteae species presented a robust phylogenetic signal and evolutive traits of the tribe. Ten hotspots of nucleotide diversity were identified, evidence of purifying selection was observed in 27 genes, and relative conservation of the plastid genomes was confirmed for Myrteae. Altogether, the outcomes of the present study provide support for planning conservation, breeding, and biotechnological programs for Plinia species.
\end{abstract}

Keyword: Jaboticaba, phylogenomic analysis, plastome evolution.

Received: July 05, 2021; Accepted: November 20, 2021.

Several studies have demonstrated that plastid genome sequences are quite useful tools for phylogenetic inferences (de Santana Lopes et al., 2018a; Machado et al., 2017, 2020; Nagel et al., 2020) and investigation of evolutionary events (de Santana Lopes et al., 2018b, 2019, Stefenon et al. 2019). Plastid genomes of some species of tribe Myrteae (Myrtaceae) have been sequenced (Eguiluz et al., 2017a, 2017b; Machado et al., 2017, 2020; Rodrigues et al., 2020) and may assist in understanding the evolution and solving taxonomic uncertainties within this tribe. The taxonomy of Myrteae has been considered particularly difficult (Vasconcelos et al., 2017) due to morphological conservatism, relatively homogeneous flowers, and the rarity of single diagnostic characters for individual clades (Lucas et al., 2019).

The scarcity of genetic and genomic resources for species of minor economic importance but with high cultural and ecological value is one of the main struggles towards conserving genetic resources and evolutionary history understanding. This is particularly true for Myrteae, which has a few species with significant genetic and genomic resources available. Aiming at generating novel genomic resources for tribe Myrteae, we sequenced, assembled, and characterized the complete plastid genomes of Plinia phitrantha (Kiaersk.) Sobral and Plinia cauliflora (Mart.) Kausel, two fruit species with high economical potential.

Send correspondence to Rubens Onofre Nodari. Universidade Federal de Santa Catarina, Departamento de Fitotecnia, Programa de Pós-graduação em Recursos Genéticos Vegetais, Rodovia Admar Gonzaga 1346, Bairro Itacorubi, 88.062-253, Florianópolis, SC, Brazil. E-mail: rubens.nodari@ufsc.br
Plastids were isolated from young and fresh leaves from single adult trees according to Machado et al. (2017). Plastidenriched DNA was isolated from the purified plastids using the CTAB protocol. Plastid DNA was sequenced on an Illumina MiSeq Sequencer platform. The paired-end reads were de novo assembled using the CLC Genomics Workbench v8.0.1. The plastid genomes annotation was performed using the DOGMA software (Wyman et al. 2004) and tRNAscan-SE (Schattner et al., 2005). Inverted Repeat regions (IRs) were identified using REPuter (Kurtz and Schleiermacher 1999). The circular cpDNA maps were built using the OrganellarGenomeDRAW program (Lohse et al., 2013).

The plastid genomes of $P$. phitrantha and $P$. cauliflora were compared based on structural features, gene content, single nucleotide polymorphisms (SNPs), insertionsdeletions (indels), synonymous $(K s)$ and nonsynonymous (Ka) substitution rates, and the $\mathrm{Ka} / \mathrm{Ks}$ ratio.

Boundaries and sizes of the IRa, IRb, SSC, and LSC regions, hotspots of sequence divergence, SSR loci, relative synonymous codon usage (RSCU), potential RNA editing sites, and phylogenomic analysis were investigated for the two newly sequenced and 13 further plastid genome sequences of species from tribe Myrteae (Table S1). The order of the genes of four Plinia species and Rhodomyrtus tomentosa (Myrtaceae) was compared through the alignment of plastid genomes using the progressive MAUVE strategy (Darling et al., 2004).

The plastid genomes of $P$. phitrantha (GenBank ID KY392759) and P. cauliflora (GenBank ID KX527622) presented $158,918 \mathrm{bp}$ and $159,095 \mathrm{bp}$ in length, respectively (Figure 1a; Table 1). The size of the long single copy region 
(LSC), the short single copy region (SSC), the IRa and IRb regions are presented in Table 1 . The total GC content of the genome was $36.96 \%$ for $P$. phitrantha and $36.97 \%$ for $P$. cauliflora. The regions LSC, SSC, and IR presented 34.8\%; $30.8 \%$, and $42.7 \%$ of the GC content respectively. These sizes are similar to those already sequenced for other species of tribe Myrteae (Eguiluz et al., 2017a, 2017b; Machado et al., 2017, 2020; Rodrigues et al., 2020; Table S1). A total of 112 different genes were identified: 78 protein-coding, 30 tRNA genes, and four rRNA genes (Table 1).
The RSCU analysis revealed the same pattern for $P$. phitrantha and $P$. cauliflora (Figure 1b). A high proportion of synonymous codons presenting the nucleotides A(30.6\%) or $\mathrm{U}(31.7 \%)$ in the third position was observed in both species. The shared pattern of codon usage bias suggests the same evolutionary path for these species and the likely absence of barriers for interspecies hybridization. Thirty codons presented RSCU values higher than 1.0, meaning they are being used more often than expected, while 32 codons are being used less frequently than expected $(\mathrm{RSCU}<1.0)$. Following Barbhuiya
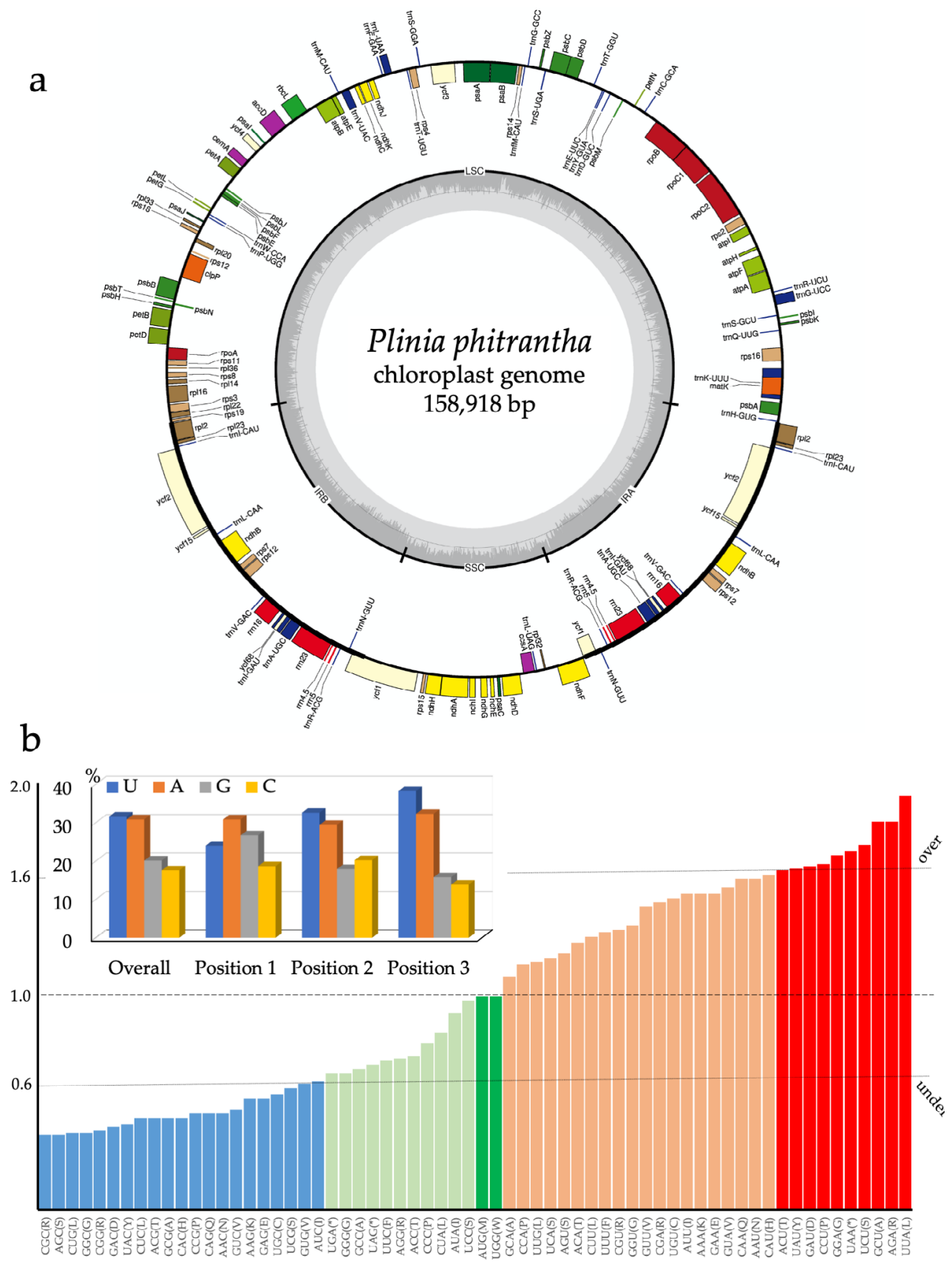

Figure 1- (a) Gene map of Plinia phitrantha plastid genome. Genes drawn inside the circle are transcribed in the clockwise direction, and genes drawn outside are transcribed in the counterclockwise direction. Different functional groups of genes are color-coded. The darker gray in the inner circle corresponds to the GC content, while the lighter gray corresponds to the AT content. LSC: large single copy, SSC: small single copy, IRa, and IRb: inverted repeat A and B, respectively. The gene map of Plinia cauliflora plastid genome is physically identical to $P$. phitrantha. (b) Relative synonymous codon usage (RSCU) analysis for P. phitrantha and P. cauliflora. The output of the analysis was equivalent for both species. The upper dotted line (over) corresponds to $\mathrm{RSCU}=1.6$ (over-representation limit), while the lower dotted line (under) corresponds to RSCU $=0.6$ (under-representation limit). RSCU $=1.0$ (dashed line) means the absence of bias in codon usage. The inset represents the frequency of each base overall and in each specific codon position. 
Table 1 - Summary of the characteristics of the plastid genomes newly sequenced in this study.

\begin{tabular}{lcc}
\hline & Plinia phitrantha & Plinia cauliflora \\
\hline GenBank ID & KY392759 039395 \\
Total number of mapped reads & $20,991,775$ & $89,204,034$ \\
Average reads length (bp) & 280.91 & 198.48 \\
Mapped reads aligned (bp) & 258.87 & 217.55 \\
Deep genome coverage & $130 \times$ & $450 \times$ \\
cpDNA genome size (bp) & 158,918 & 159,095 \\
LSC size in bp & 88,204 & 88,162 \\
SSC size in bp & 18,462 & 18,615 \\
IR size in bp & 26,126 & 26,159 \\
PCG genes & 78 & 78 \\
tRNA genes & 30 & 30 \\
rRNA genes & 4 & 4 \\
Genes duplicated by IR & 20 & 20 \\
Genes with introns & 18 & 18 \\
Overall GC content (\%) & 36.96 & 36.97 \\
GC content in the LSC (\%) & 34.8 & 34.8 \\
GC content in the SSC (\%) & 30.8 & 30.8 \\
GC content in the IR (\%) & 42.7 & 42.7 \\
\hline
\end{tabular}

cp: chloroplast; PCG: protein-coding gene; ${ }^{\$} \mathrm{n}^{\circ}$ of sequenced bases/estimated plastid genome size

et al. (2020), a total of 21 codons are under-represented (RSCU $<0.60$ ), and 10 codons are over-represented (RSCU > 1.6).

A total of 353 single nucleotide polymorphisms (SNPs) and 574 indels ranging from one to 17 bases between $P$. phitrantha and $P$. caulifora were identified. The SNPs were located within 33 genes, seven introns, and 55 intergenic regions (Figure 2).

The highest nonsynonymous rate was observed in the pet $B$ gene $(\mathrm{Ka}=0.7376)$, while the $r b c L$ gene had the highest synonymous rate $(\mathrm{Ks}=0.8675)$. No changes were observed in the synonymous or nonsynonymous rates in 44 genes. Evidence of purifying selection $(\mathrm{Ka} / \mathrm{Ks}$ ratio $<1.0)$ was observed in three genes associate with the small subunit of the ribosome (rps3, rps 4, and rps 12), two with the large subunit of the ribosome (rpl23 and rpl32), two with the RNA polymerase subunits ( $r p o A$ and $r p o C 1$ ), three with the ATP synthase gene (atpA, $a t p B$, and $a t p E$ ), five with the NADH dehydrogenase ( $n d h A$, $n d h D, n d h F, n d h H$, and $n d h K)$, two with the cytochrome $\mathrm{b} / \mathrm{f}$ complex (petA and petB), two with the photosystem I ( $p s a A$ and $p s a B$ ), four with the photosystem II ( $p s b A, p s b B, p s b C$, and $p s b K)$, two with unknown functions ( $y c f 1$ and $y c f 2)$, in the cytochrome $\mathrm{c}$ biogenesis $(\operatorname{css} A)$, in the acetyl-CoA carboxylase $(a c c D)$, and the maturase ( $m a t K)$ genes. No evidence of positive selection $(\mathrm{Ka} / \mathrm{Ks}$ ratio $>1.0)$ was observed.

Using the plastid genome of Arabidopsis thaliana as a reference, a total of 459 RNA editing sites were predicted for $P$. phitrantha and 458 for $P$. cauliflora. No silent putative editing site was predicted. Most of the editing sites (ca. 98.3\%) were shared between species. The correspondence of these sites in $P$. phitrantha and $P$. cauliflora suggests a lack of incompatibility for interspecific hybridization since RNA editing affects plastid gene expression and, therefore, could be involved in nuclear-cytoplasmic incompatibility in interspecific hybrids (Pacheco et al., 2020).
Concerning the SSR loci identified in the plastid genomes, the $\mathrm{A} / \mathrm{T}$ motif was the most frequent. The monomer motif C/G was found only in E. selloi and P. dioica, TAT/ATA only in C. xanthocarpa, ACT/AGT only in $R$. tomentosa, and AAT/ATT in E. selloi, P. clatteyanum, and P. guajava. The outgroup species (Corymbia eximia, Allosyncarpia ternata, and Lagerstroemia fauriei) presented a similar pattern of motifs occurrence (Figure S1).

The phylogenomic analysis (Figure 3) based on the complete plastid sequences using Corymbia eximia (Eucalypteae, Myrtaceae; NC022409), Allosyncarpia ternata (Eucalypteae, Myrtaceae; NC02243), and Lagerstroemia fauriei (Myrtales, Lythraceae; NC029808) as outgroups returned an overall topology congruent to that based on nuclear and plastid genes. The Plinia group ( $\mathrm{BP}=100 \%)$ is a sister of the group formed by all other Myrteae South American species. Eugenia and Psidium also formed monophyletic groups (BP $=100 \%)$. The Eugenia group is related to Myrcianthes pungens, while Acca sellowiana is a sister of C. xanthocarpa (BP $=99 \%)$. The Australasian Myrteae R. tomentosa is basal to the South American species. This result supports previously published phylogenetic studies of tribe Myrteae based on nuclear and plastid DNA sequences (Vasconcelos et al., 2017).

In all species, the IRb/LSC border is located between genes $r p l 2$ and rps19, while the $y c f 1$ gene highlights the IRa/SSC junction, crossing across both genomic regions (Figure S2). The analysis of local collinear blocks (LCBs) architecture within the plastid genomes of Rhodomyrtus tomentosa (the earliest divergent species within Myrtaeae) and the four Plinia species revealed two main LCBs with four short regions with diverse distribution or occurrence among these plastomes (Figure S2).

The sliding window analysis generated a consensus of $169,244 \mathrm{bp}$ and revealed 10 hotspots of nucleotide divergence 

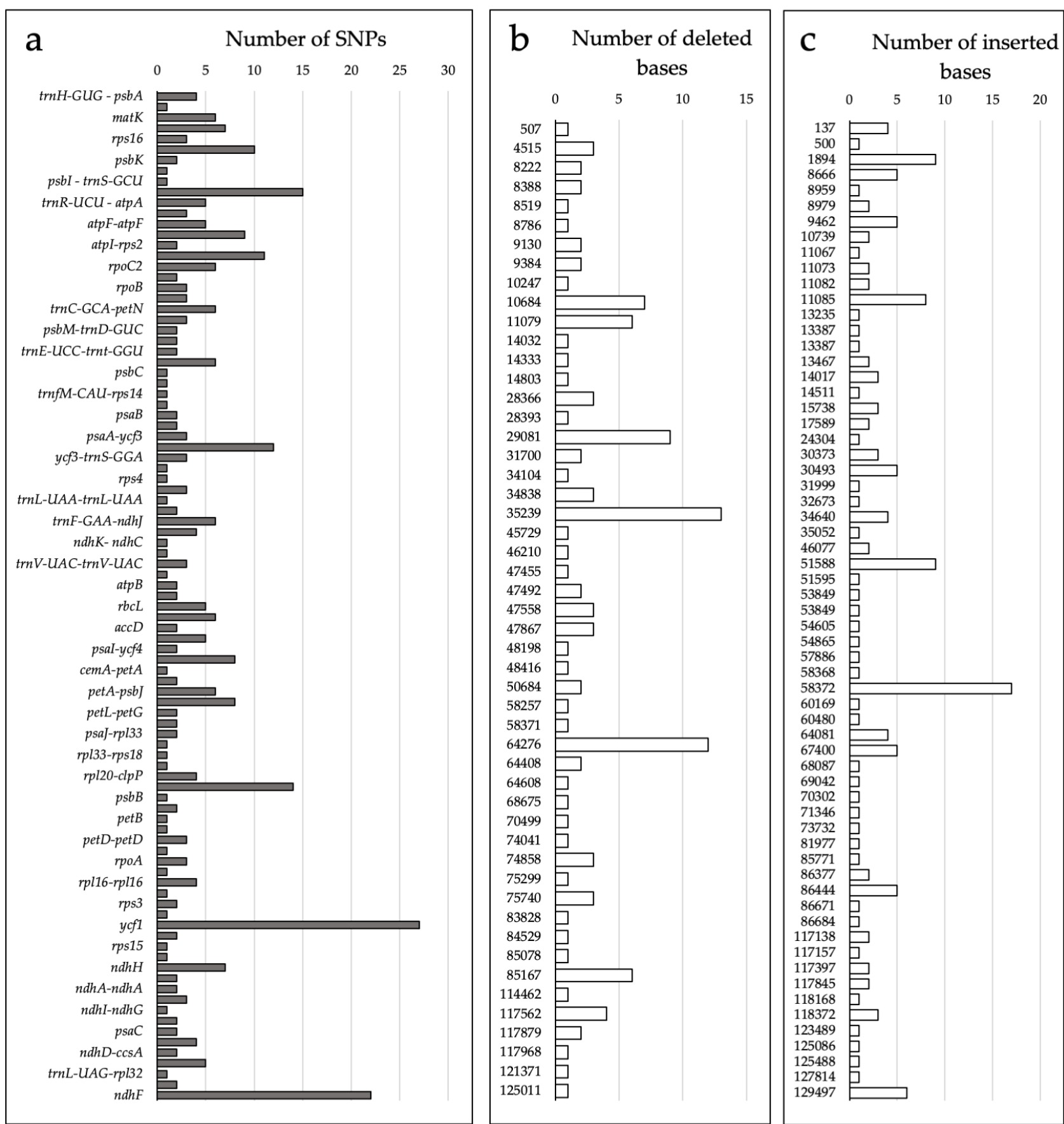

Figure 2 - Distribution of SNPs and indels prospected in the comparison between the plastid genomes of $P$. phitrantha and $P$. cauliflora. (a) Number of SNPs in different regions of the plastid genomes. (b) Number of deleted bases in the plastid genome of $P$. phitrantha in comparison to $P$. cauliflora. (c) Number of inserted bases in the plastid genome of $P$. phitrantha in comparison to $P$. cauliflora. The numbers in the $\mathbf{y}$-axis of $\mathbf{b}$ and $\mathbf{c}$ correspond to the genomic position, starting from the IRa region in an anti-clock direction.

with $\pi>0.040$, a value five-fold higher than the overall nucleotide diversity ( $\pi=0.00725$ ) estimated for the whole plastid genome. Six of these hotspots are in intergenic spacer regions (IGS), two are in intronic regions, one corresponds to a gene $(n d h \mathrm{~K})$, and one includes part of an intron and part of the second exon of the $c l p \mathrm{P}$ gene (Figure S3). Considering the puzzling taxonomic classification of Plinia species based on morphological traits (dos Santos et al. 2021), these polymorphic regions, the SNPs, and the indels identified between $P$. phitrantha and $P$. caulifora are promising sources of taxonomic markers for Plinia species.
Even an inversion observed in the SSC region of the plastid genomes of P. phitrantha, P. edulis, and E. pyriformis is not an irregular event (Walker et al., 2015). Chloroplast DNA within individual plants can exhibit a form of heteroplasmy in which the plastome exists in two equimolar states (inversion isomers) that differ in the relative orientation of the SSC region (Palmer, 1983; Walker et al., 2015). Finally, the conservation of the plastid genomes is corroborated by the analysis of LCBs. Only four small regions differ among Plinia species and $R$. tomentosa, whereas the main CLBs are conserved through the five plastid genomes (Figure S4). 


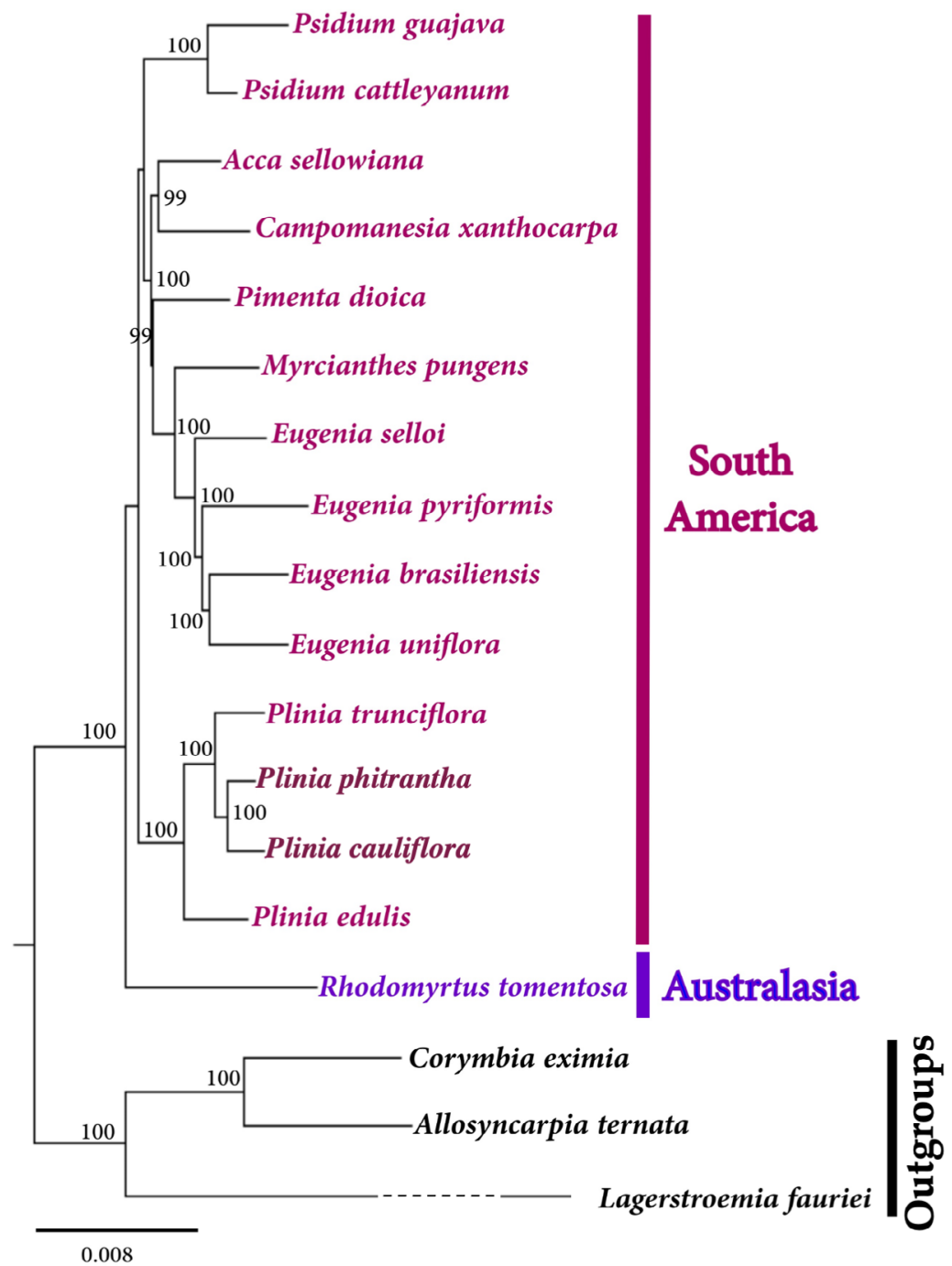

Figure 3 - Maximum likelihood phylogenomic relationship among species of tribe Myrteae based on whole plastid genome sequences. $C$. eximia, $A$. ternata, and L. fauriei were used as outgroups. Numbers at the nodes are bootstrap support after 1000 permutations. The branch length of $L$. fauriei was shortened in the figure (dashed line).

Patterns of structural conservation and synteny among six plastid genomes of Myrteae species were also reported by Rodrigues et al. (2020). Here we show that such preserved patterns were shared with $R$. tomentosa, an earlier divergent species within Myrtaceae (Vasconcelos et al., 2017).

\section{Acknowledgments}

This work was funded by the Fundação de Amparo à Pesquisa e Inovação do Estado de Santa Catarina (FAPESC Projects 14848/2011-2 and 2780/2012-4). We also thank the Coordenação de Aperfeiçoamento de Pessoal de Nível Superior (CAPES) - (Finance code 001) for scholarships to LOM, the Conselho Nacional de Desenvolvimento Científico e Tecnológico (CNPq) for fellowships to VMS, LNV, and RON, and to the Nucleus of Nitrogen Fixation of Universidade Federal do Paraná for DNA sequencing.

\section{Conflict of Interest}

The authors declare no conflict of interest.

\section{Author Contributions}

LOM, VMS and RON conceived and designed the experiments. RON and VMS supervised the study. LOM performed the experiment. LOM performed the wet lab analysis. LOM, LNV, and VMS performed the bioinformatics analysis. LOM, LNV, VMS, and RON wrote the manuscript. All authors read and approved the final manuscript.

\section{References}

Barbhuiyaa PA, Uddinb A and Chakrabortya S (2020) Analysis of compositional properties and codon usage bias of mitochondrial CYB gene in anura, urodela and gymnophiona. Gene 751:144762.

Darling ACE, Mau B, Blattner FR and Perna NT (2004) Mauve: Multiple alignment of conserved genomic sequence with rearrangements. Genome Res 14:1394-1403.

de Santana Lopes A, Gomes Pacheco T, do Nascimento Vieira L, Guerra MP, Nodari RO, Maltempi de Souza E, de Oliveira Pedrosa F and Rogalski M (2018a) The Crambe abyssinica plastome: Brassicaceae phylogenomic analysis, evolution of RNA editing sites, hotspot and microsatellite characterization of the tribe Brassiceae. Gene 671:36-49. 
de Santana Lopes A, Gomes Pacheco T, Nimz T, do Nascimento Vieira L, Guerra MP, Nodari RO, de Souza EM, de Oliveira Pedrosa F and Rogalski M (2018b) The complete plastome of macaw palm [Acrocomia aculeata (Jacq.) Lodd. ex Mart.] and extensive molecular analyses of the evolution of plastid genes in Arecaceae. Planta 247:1011-1030.

de Santana Lopes A, Gomes Pacheco T, Nascimento da Silva O, Magalhães Cruz L, Balsanelli E, Maltempi de Souza E, de Oliveira Pedrosa F and Rogalski M (2019) The plastomes of Astrocaryum aculeatum G. Mey. and A. murumuru Mart. show a flip-flop recombination between two short inverted repeats. Planta 250:1229-1246.

dos Santos DD, de Oliveira LO, Beise DC, Machado LO and Stefenon VM (2021) Biotechnology in Plinia sp: needs and perspectives for a neglected group of fruit species. Bio Vegetal 21:3-14.

Eguiluz M, Rodrigues NF, Guzman F, Yuyama P and Margis R (2017a) The chloroplast genome sequence from Eugenia uniflora, a Myrtaceae from Neotropics. Plant Syst Evol 303:1199-1212.

Eguiluz M, Yuyama PM, Guzman F, Rodrigues NF and Margis R (2017b) Complete sequence and comparative analysis of the chloroplast genome of Plinia trunciflora. Genet Mol Biol 40:871-876.

Kurtz S and Schleiermacher C (1999) REPuter: Fast computation of maximal repeats in complete genomes. Bioinformatics $15: 426-427$

Lohse M, Drechsel O, Kahlau S and Bock R (2013). OrganellarGenomeDRAW - a suite of tools for generating physical maps of plastid and mitochondrial genomes and visualizing expression data sets. Nucleic Acids Res 41:W575-W581.

Lucas EJ, Holst B, Sobral M, Mazine FF, Lughadha, EMN, Proença CEB, da Costa IR and Vasconcelos TNC (2019) A new subtribal classification of Tribe Myrteae (Myrtaceae). Syst Bot 44:560-569.

Machado LO, Vieira LN, Stefenon VM, Oliveira Pedrosa F, Souza EM, Guerra MP and Nodari RO (2017) Phylogenomic relationship of feijoa (Acca sellowiana (O.Berg) Burret) with other Myrtaceae based on complete chloroplast genome sequences. Genetica 145:163-174.

Machado LO, Vieira LN, Stefenon VM, Faoro H, Pedrosa FO, Guerra MP and Nodari RO (2020) Molecular relationships of Campomanesia xanthocarpa within Myrtaceae based on the complete plastome sequence and on the plastid $y c f 2$ gene. Genet Mol Biol 43:e20180377.

Nagel J, Machado LO, Lemos RPM, D’Oliveira Matielo CB, Poletto T, Poletto I and Stefenon VM (2020) Structural, evolutionary and phylogenomic features of the plastid genome of Carya illinoinensis cv. Imperial. Ann For Res 63:3-18.

Pacheco TG, Lopes AS, Welter JF, Yotoko KSC, Otoni WC, Vieira LDN, Guerra MP, Nodari RO, Balsanelli E, Pedrosa FO et al.
(2020) Plastome sequences of the subgenus Passiflora reveal highly divergent genes and specific evolutionary features. Plant Mol Biol 104:21-37.

Palmer J (1983) Chloroplast DNA exists in two orientations. Nature 301:92-93.

Rodrigues NF, Balbinott N, Paim I, Guzman F and Margis R (2020) Comparative analysis of the complete chloroplast genomes from six Neotropical species of Myrteae (Myrtaceae). Genet Mol Biol 43:e20190302.

Schattner P, Brooks AN and Lowe TM (2005) The tRNAscan-SE, snoscan and snoGPS web servers for the detection of tRNAs and snoRNAs. Nucleic Acids Res 33:W686-W689.

Stefenon VM, Klabunde G, Lemos RPM, Rogalski M and Nodari RO (2019) Phylogeography of plastid DNA sequences suggests postglacial southward demographic expansion and the existence of several glacial refugia for Araucaria angustifolia. Sci Rep 9:2752

Vasconcelos TNC, Proença CEB, Ahmad B, Aguilare DS, Aguilar R, Amorim BS, Campbell K, Costa IR, De-Carvalho PS, Faria JEQ et al. (2017) Myrteae phylogeny, calibration, biogeography and diversification patterns: Increased understanding in the most species rich tribe of Myrtaceae. Mol Phylogenet Evol 109:113-137.

Walker JF, Jansen RK, Zanis MJ and Emery NC (2015) Sources of inversion variation in the small single copy (SSC) region of chloroplast genomes. Am J Bot 102:1751-1752.

Wyman SK, Jansen RK and Boore JL (2004) Automatic annotation of organellar genomes with DOGMA. Bioinformatics 20: 3252-3255.

\section{Supplementary material}

The following online material is available for this article:

Table S1 - Comparative summary of some features of the Myrtaceae plastid genomes included in this study

Figure S1 - (a) Distribution of the SSR loci within the plastid genome of $P$. phitrantha and P. cauliflora.

Figure S2 - Boundaries at the junctions of the LSC, IRb, IRa, and SSC regions of the plastid genomes of South American Myrteae species.

Figure S3 - Sliding window analysis of the plastid genomes of 15 Myrteae species.

Figure S4 - Multiple plastid genome alignment with four Plinia species and R. tomentosa.

\section{Associate Editor: Dario Grattapaglia}

License information: This is an open-access article distributed under the terms of the Creative Commons Attribution License (type CC-BY), which permits unrestricted use, distribution and reproduction in any medium, provided the original article is properly cited. 